BULLETIN Bulletin hispanique

HISPANIQUE Université Michel de Montaigne Bordeaux

109-1 | 2007

Varia

\title{
El Cantar de los Cantares de fray Luis de León
}

¿Una traducción original?

Sergio Fernández López

\section{(2) OpenEdition}

Journals

Edición electrónica

URL: http://journals.openedition.org/bulletinhispanique/82

DOI: 10.4000/bulletinhispanique.82

ISSN: 1775-3821

Editor

Presses universitaires de Bordeaux

\section{Edición impresa}

Fecha de publicación: 1 junio 2007

Paginación: 17-45

ISBN: 978-2-85276-094-3

ISSN: 0007-4640

Referencia electrónica

Sergio Fernández López, "El Cantar de los Cantares de fray Luis de León », Bulletin hispanique [En línea], 109-1 | 2007, Publicado el 01 junio 2010, consultado el 08 mayo 2019. URL : http://

journals.openedition.org/bulletinhispanique/82 ; DOI : 10.4000/bulletinhispanique.82 


\title{
El Cantar de los Cantares de fray Luis de León: ¿Una traducción original?
}

\author{
Sergio Fernández López \\ Universidad de Huelva - Espagne
}

La traduction romane du Cantar de los Cantares de Fray Luis de León a reçu de multiples éloges provenant des plus diverses disciplines. Effectivement, le génie créateur du moine augustinien s'est souvent montré insultant. Cependant, il semble peu probable qu'une version aussi parfaite ait été la première dans son genre. Fray Luis connaissait parfaitement la longue tradition des versions judéo-romanes de la Bible, versions qui ont influencé sa propre traduction. La confrontation de textes que je présente dans cet article, bien qu'elle ne soit pas exhaustive, ne laisse plus de doutes à cet égard, même si elle diminue la réputation d'originalité de la traduction du maître de Salamanque. En tout cas, la grande réussite de Fray Luis fut sans doute de mettre à la portée des humanistes postérieurs cette branche du savoir enracinée dans le judaïsme le plus érudit.

La traducción romance del Cantar de los Cantares llevada a cabo por fray Luis de León ha recibido innumerables elogios procedentes de las más diversas disciplinas. Y es que el genio creador del fraile agustino ha resultado a menudo insultante. Sin embargo, parece poco probable que una versión tan perfecta pudiera ser la primera en su orden. El conquense poseía a sus espaldas una larga tradición de versiones biblicas judeorromances que conocía perfectamente y que conformó la base de su propia traducción. El cotejo que presento en este artículo, si bien no exhaustivo, si suficiente y esclarecedor en ese sentido, apenas deja lugar a la duda, pese a la evidente merma que ello supondría para la elogiada originalidad de la traducción del maestro salmantino. En cualquier caso, y creo que éste fue su verdadero logro, poner al servicio de posteriores humanistas aquella rama restringida del saber, enraizada en el judaismo más erudito, resultaba una actitud que le era digna de encomio.

$B H i$, Tome 109, n 1 - juin 2007 - p. 17 à 45. 
The Romance translation of the Song of Songs by Fray Luis de León has received countless eulogies by scholars from different fields. The Augustinian monk's genius has proved even offensive. However, it seems unlikely that such a perfect rendering had been the first of its kind. Fray Luis was well acquainted with a long tradition of Judaicromance Biblical versions which shaped the basis of his own translation. The comparison that I offer in this article, if not exhaustive, is clarifying enough in that direction, and it leaves little room for doubt, in spite of the obvious discredit this could entail for the frequently praised originality of the translation by the Salamanca master. In any caseand I think this was his real accomplishment - the legacy to later humanists of that rare branch of knowledge, rooted in the most learned Judaism, was a task worthy of praise.

Mots-clés : Cantique de Cantiques - Fray Luis de León - Bibles judéo-romanes Traductions bibliques.

\section{INTRODUCCIÓN}

T As obras del célebre agustino fray Luis de León han gozado de L considerable prestigio dentro de las letras hispánicas y europeas. Las modernas ediciones de obras como La Perfecta Casada dan fiel muestra de la vitalidad que aún poseen los escritos del humanista conquense. Sin embargo, desde su primitiva publicación (1798) y casi por encima de aquellos conocidos tratados, cumbres del Renacimiento, su hermosa Exposición literal del Cantar de los Cantares se ha venido alzando hasta acaparar la atención de los más prestigiosos investigadores de los dos últimos siglos.

Los motivos a los que respondía aquel nunca desorbitado interés podrían ser legión: quizá, el hecho de tratarse de una obra primeriza, casi de juventud; las sugerentes e indudables reminiscencias erótico-amorosas del libro bíblico tratado, apenas reconocidas por las tradiciones judía y cristiana, como si Dios no fuera amor por encima de todas las cosas ${ }^{1}$; las hermosas e

1. En la tradición cristiana el Cantar de los Cantares fue interpretado desde la antigüedad como la relación entre el Esposo (Dios) y su Esposa (la Iglesia). Esta temprana explicación pudo a su vez provocar como reacción lógica una lectura alegórica del libro bíblico entre los judíos. De este modo, el libro se convirtió en manos de estos últimos en la historia de Dios y el pueblo elegido. Esta interpretación resurgió con fuerza entre los exégetas hebreos de la Edad Media, quizás por su delicada posición y por las continuas persecuciones a que se vieron sometidos. Necesitaban, pues, ver en el Cantar de los Cantares un libro de esperanza interpretado en clave de liberación. El libro bíblico vino a simbolizar entonces la historia de Israel desde el exilio en Egipto hasta la definitiva salvación que traería el rey Mesías. Sin embargo, la controversia generada en torno a su carácter de libro inspirado y a su apropiada o inapropiada introducción en el canon bíblico, acompañó al Cantar de los Cantares desde sus orígenes. No es este el momento de entrar en discusiones teológicas, pero es evidente 
inigualables descripciones del maestro salmantino; el que le costase, entre otros motivos, un largo y duro procesamiento que dio con sus huesos en las insalubres cárceles inquisitoriales; el haber puesto en manos de cerriles teólogos una obra de evidentes herencias exegético-judías, fruto de una época, pero también, no se olvide, de un ser con características concretas e individualizadoras, etc.

Todo ello y más ha hecho del Cantar de los Cantares, probablemente, la obra más estudiada de entre los escritos luisianos en los últimos tiempos. A. Sáenz Badillos, que llegó a calificarla como «una de las obras más representativas de nuestro Renacimiento", estudió su planteamiento general, así como su conexión con otros comentarios anteriores ${ }^{2}$. Ciriaco Morón Arroyo se centró en aspectos como la teología bíblica del tratado y su carácter filológico ${ }^{3}$. Olegario García de la Fuente resaltó las características de la traducción ${ }^{4}$, mientras Avelina Carrera de la Red subrayaba la sabiduría humanística que rezumaba el comentario ${ }^{5}$. Pero evidentemente han sido muchos más los investigadores que han venido abordando su estudio y no menos los aspectos que se han anotado al respecto, tales como la idea del amor y la mujer defendida en sus glosas ${ }^{6}$, el estilo literario de la obra ${ }^{7}$, o la

honda huella que dejaron en sus numerosas interpretaciones ciertos exégetas

que el Cantar describe a priori una simple historia de amor y nada podía ejemplificar mejor la naturaleza divina. Dios también es amor y esto parece que nunca llegó a entenderse ni entre judíos ni entre cristianos, que siempre necesitaron una explicación ulterior ante lo que creyeron casi un libro obsceno.

2. «En torno a dos comentarios al Cantar de los Cantares», Helmantica, 46, 1995, p. 158176.

3. «Espesor de la letra. La hermenéutica de fray Luis de León», en Fray Luis de León. Historia, Humanismo y Letras, eds. V. García de la Concha y J. San José Lera, Salamanca, Universidad, 1996, p. 299-312; idem, «Fray Luis de León: Sistema y drama», en Fray Luis de León. Aproximaciones a su vida y su obra, eds. C. Morón Arroyo y M. Revuelta Sañudo, Santander, Sociedad Menéndez Pelayo, 1989, p. 311-335.

4. "Fray Luis, traductor del Cantar de los Cantares», en Actas del VIII Congreso Español de Estudios Clásicos, vol. III, Madrid, Ediciones Clásicas, 1994, p. 433-438.

5. «Lengua y cultura humanísticas en el Cantar de los Cantares de fray Luis de León», Anuario de Estudios Filológicos, 11, 1988, p. 83-107.

6. E. Fernández Tejero, «Del amor y la mujer en Cipriano de la Huerga y Luis de León», en Cipriano de la Huerga, Obras Completas, Vol. IX, León, Universidad, 1996, p. 13-32.

7. R. Çao Martínez, "El estilo de fray Luis a la luz de un cuadernillo autógrafo de la Exposición del Cantar de los Cantares", en Fray Luis de León. Historia, Humanismo y Letras, ed. cit., p. 571-608. 
judíos ${ }^{8}$.

Sin embargo, no por esta razón han dejado de existir en derredor de la mencionada Exposición literal numerosas interrogantes. Ya José M. Blecua había anotado algunas de aquellas dificultades cuando abordó su edición. Era evidente que no todos los manuscritos conservados, dispares entre sí, podían ser fruto de la pluma del agustino. Sus diferencias debían de explicarse antes como consecuencia de la transmisión, que como refundiciones o correcciones propuestas por el propio humanista. De hecho, sería difícil de creer que fray Luis hubiera llegado a corregir siete u ocho veces la obra primigenia. De ahí que José Manuel Blecua defendiera de forma acertada, en principio, la posibilidad de que su Exposición saliera ya alterada de los numerosos conventos por los que pasó ${ }^{9}$.

Pero si el panorama no resultaba nada despejado de dificultades, a enrevesarlo -o a aclararlo-, vino la posterior aparición de al menos cinco testimonios más del comentario literal, no manejados en la edición de José Manuel Blecua, junto a otros dos que transmitían una Exposición del Cantar de los Cantares en 'sentido espiritual', recientemente publicados ${ }^{10}$. Por lo que respecta a la autoría de este último tratado con interpretaciones alegóricas, todo apuntaba al maestro salmantino. Así lo subrayaba su moderno editor; también por esa misma tesis se decantaba finalmente el descubridor de los manuscritos, aunque no sin advertir antes la posibilidad de que perteneciera a otros humanistas afines a fray Luis, como Cipriano de la Huerga, su maestro, o Arias Montano, su amigo y condiscípulo ${ }^{11}$.

El presente estudio, obviamente, no soluciona todas aquellas trabas y embarazos, pero sí puede arrojar cierta luz sobre la elaboración de la obra desde el punto de vista de la traducción. Hasta el momento, y pese a aquella

8. A. Habib Arkin, La influencia de la exégesis hebrea en los comentarios bíblicos de Fray Luis de León, Madrid, Instituto Benito Arias Montano-CSIC, 1966.

9. Vid. Fray Luis de León, Cantar de los Cantares de Salomón, ed. José Manuel Blecua, Madrid, Gredos, 1994, p. 36 (en adelante, Cantares-Blecua).

10. Fray Luis de León, El Cantar de los Cantares de Salomón, ed. José María Becerra Hiraldó, Madrid, Cátedra, 2003. Sobre la atribución del tratado espiritual del Cantar al maestro salmantino afirma su moderno editor: «Entiendo que el presente comentario del Cantar de los Cantares, motivo permanente de reflexión y enseñanza en fray Luis, es un escalón intermedio entre la primera Exposición literal y la última Triplex Explanatio». Sobre la posible autoría he llevado a cabo un breve estudio de próxima publicación que vincula esta «Exposición espiritual» con el humanista Benito Arias Montano.

11. K. Reinhardt, «Una exposición castellana del Cantar de los Cantares, hasta ahora desconocida, atribuida a fray Luis de León", Fray Luis de León. Historia, Humanismo y Letras, ed. cit., p. 471-483. 
considerable atención ya referida, la Exposición literal de fray Luis continúa sin haber sido abordada atendiendo a las influencias que pudieron regir en su elogiada versión romance del Cantar de los Cantares. Su perfección, con las solas excepciones de ciertos estudiosos no exentos de prejuicios, se ha visto respaldada por el conjunto de la crítica. Lejos de constituir una versión sin soltura, servil y carente de gracia, la traducción del agustino participaba de una belleza singular, hasta el punto de que, según A. Custodio Vega, «en comparación con las versiones clásicas, las sagradas suponen una elevación, pureza y valentía que en vano se buscarán en aquéllas. Fray Luis no perdería mucho con perder sus traducciones clásicas, pero sí perdería enormemente con la pérdida de sus versiones sagradas. Tiene una docena de versiones que superan con mucho a las mejores similares del mundo y aun rivalizan en belleza y movimiento con los mismos originales» ${ }^{12}$.

No muy distinta sería la posterior opinión de Emilia Fernández Tejero: «fray Luis se mueve con ligereza, con brillantez, además de naturalmente, de con gran conocimiento, por el texto hebreo del Cantar. La sensación que provoca la lectura de su traducción es la de libertad, que el conocimiento no frena sino que, por el contrario, enriquece» ${ }^{13}$.

Sin embargo, una traducción tan perfecta y conseguida difícilmente podía considerarse el inicio de una saga posterior de traducciones, ni podía constituir la primera en su orden. La versión romance del catedrático salmantino no tenía nada de tanteo o ejercicio experimental, como sí lo tenían los sonetos del marqués de Santillana; y ello, ni aun considerando cierta la posibilidad de que la escribiera sin ninguna pretensión artística y con la sola intención de enseñársela a la monja Isabel de Osorio, su prima. En efecto, la traducción de fray Luis poseía una larga tradición a sus espaldas de la que bien pudo servirse y a la que apenas se le ha prestado atención, cuando gracias a aquélla podían salvarse algunas de las incógnitas que hasta el momento no han recibido una solución definitiva.

En el sur de Europa existieron traducciones bíblicas desde el mismo nacimiento de las lenguas vernáculas. En los reinos hispanos, además, aquellos romanceamientos bíblicos, lejos de tener como texto subyacente la Vulgata latina, fueron traducidos en su mayoría basándose en el texto hebreo, aunque tampoco faltaron aquellos que se apoyaron en la traducción de san Jerónimo. En todo caso, si algo peculiariza las primitivas versiones medievales peninsulares del resto de traducciones bíblicas europeas es

12. A. Custodio Vega, Fray Luis de León, Poesías, Barcelona, Planeta, 1988, p. LV.

13. «Fray Luis de León, hebraísta», Sefarad, 48, 1988, p. 276-277. 
precisamente que las de Sefarad pueden llamarse con todo derecho versiones judeorromances, escasas cuando no inexistentes en otros países vecinos. $\mathrm{Y}$ a ellas debió acudir el humanista.

\section{FRAY LUIS DE LEÓN, CONOCEDOR DE LAS TRADUCCIONES BÍBLICAS MEDIEVALES}

La lectura de la Biblia en lengua vulgar estuvo prohibida a lo largo de toda la Edad Media en los distintos reinos hispanos, cuando menos en tierras fronterizas, susceptibles de ser influidas por creencias foráneas de signo herético. Lo mismo cabía afirmar de las zonas que ya gozaban de una importante tradición bíblica, particularmente en aquellos lugares donde las academias rabínicas habían alcanzado considerable prestigio. Tal fue el caso de Barcelona o Tarragona, primeros territorios que vieron prohibidas la vulgarización de las Escrituras.

Sin embargo, ni aquellas primitivas prohibiciones, ni las posteriores censuras publicadas en tiempos de los Reyes Católicos ${ }^{14}$, ni siquiera los ulteriores índices inquisitoriales, pudieron acabar con la existencia y la transmisión de las biblias judeorromances ${ }^{15}$. Es cierto que la mayor parte acabaron en públicas hogueras, pero no lo es menos que algunas de ellas llegaron a las manos de nuestros más prestigiosos humanistas.

En efecto, la primera y principal empresa que acometió Arias Montano tras ser nombrado Bibliotecario Mayor de El Escorial fue precisamente escribir al entonces inquisidor general, el cardenal Gaspar de Quiroga, para que éste le remitiese las biblias que se encontraran secuestradas en el Consejo de Inquisición. No mucho después, el frexnense habría de escribir al embajador de Espańa en Roma, don Juan de Zúñiga, solicitándole un breve en favor de Felipe II y de su real Biblioteca, con el cual les quedara permitido la custodia de libros prohibidos. Todo ello ocurría en el último tercio del siglo XVI, entre 1577 y 1578 más exactamente ${ }^{16}$. Desde entonces,

14. Para la censura de las biblias judeorromances y sus consecuencias en tiempos de los Reyes Católicos puede verse un resumen en Sergio Fernández López, «Del orto al ocaso de las traducciones bíblicas judeorromances", Ínsula, 691-92, 2004, p. 24-26.

15. Vid. Sergio Fernández López, Lectura y Prohibición de la Biblia en lengua vulgar. Defensores y detractores, León, Universidad, 2003.

16. Vid. Sergio Fernández López, «El manuscrito I-I-3 y Arias Montano. (La labor de Benito Arias en la conservación de las biblias romances escurialenses)", en Humanae Litterae. Estudios de Humanismo y tradición clásica en homenaje al profesor Gaspar Morocho Gayo, ed. J. F. Domínguez Domínguez, Colección Humanistas Españoles, vol. 28, León, Universidad, 2004, p. 169-190. 
tanto Arias Montano como el círculo montaniano, entre los que estaba incluido por supuesto el fraile agustino, tuvieron la oportunidad de consultar biblias judeorromances, algunas de ellas aún conservadas en el monasterio escurialense ${ }^{17}$.

La presencia de aquellas traducciones en los escritos humanísticos de carácter bíblico posteriores a aquellas fechas queda fuera de duda. Entre otros, Benito Arias las cita expresamente en su tratado sobre Jueces y las utiliza en su comentario a Josué. Pero los humanistas ya las conocían desde hacía décadas. De otra manera, no se explicarían las asombrosas coincidencias que relacionaban la traducción y comentario de fray Luis al Cantar de los Cantares o al libro de Job con algunos manuscritos bíblicos conservados. Ello retrotraía de forma necesaria la fecha en la que algunos de los humanistas más conocidos debieron de toparse por vez primera con las comentadas traducciones. En este sentido, la Universidad de Alcalá desempeñaría un importantísimo papel y sería fray José de Sigüenza quien nos lo haría saber.

Estaba claro que los trabajos preparatorios de la Biblia Complutense, entre otros aspectos, habían propiciado que los fondos de la biblioteca alcalaína superaran en importancia no sólo a los de las restantes bibliotecas españolas, sino aun a los de muchas universidades europeas. No era de extrañar, por tanto, que formando parte de su fondo bíblico, tanto hebreo, como griego y latino, también adornaran sus anaqueles algunas biblias judeorromances, sobre todo, teniendo en cuenta la proximidad de una judería tan surtida ellas como fue la de Toledo. Sobre la biblioteca alcalaína llegaría a comentar uno de los más destacados discípulos de Arias Montano, el mencionado fray José de Sigüenza:

En las Biblias nuestras antiguas, se entienden de algunos volúmines antiquísimos escritos en caracteres góticos, los quales consta aver quedado como por reliquias desde la destruición de España, y se hallaron en la ciudad de Toledo; después fueron puestos en la librería de Alcalá. Están también allí otros volúmines que, aunque no son atán antiguos como los primeros, encuadran en ellos admirablemente. Estas Biblias antiguas todas vienen tan puntuales con el hebreo, que lo que agora vemos en nuestras Biblias ordinarias

17. Entre ellas pueden citarse las contenidas en los manuscritos de sobra conocidos, I-I-3 (E3), I-I-4 (E4), I-I-5 (E5), I-I-7 (E7) y J-II-19 (E19). De las versiones que tuvieron como texto subyacente la Vulgata latina podrían citarse las conservadas en los dos manuscritos más famosos, I-I-6 e I-I-8. Para una descripción detallada y reciente de los mismos, vid. Gemma Avenoza, La Biblia de Ajuda y la Megil. lat Antiochus en romance, CSIC, Madrid, 2001, p. 24-26. 
es vicio de los escritores e impresores ${ }^{18}$.

Así pues, el duro escollo que supuso en el camino de las biblias judeorromances la pragmática dictada en tiempos de los Reyes Católicos no obstó para que éstas llegaran a los ojos de los más afamados escriturarios. $\mathrm{Ni} \tan$ siquiera los durísimos índices inquisitoriales pudieron evitarlo. La desmedida persecución a que se vieron sometidas las traducciones bíblicas desde finales del siglo XV hacía creer en un brusco corte sin solución de continuidad y nos dejaba una sensación de cierta incredulidad ante la posibilidad de que los humanistas las hubiesen tenido entre sus manos. Con todo, aquellos que pasaron por el Colegio de Alcalá las conocieron y consultaron, fray Luis incluido, por supuesto.

\section{LAS BIBLIAS JUDEORROMANCES Y LA TRADUCCIÓN DE FRAY LUIS DE LEÓN}

El comentario romance al Libro de Job le llevó al maestro salmantino varios años de elaboración. Es probable que el hastío de ver siempre inacabada aquella obra interminable actuara en detrimento de la calidad de su traducción. Sea como fuere, el fraile agustino no buscó en este caso una versión personalizada, sino que, por el contrario, copió sin reservas la traducción de una de las versiones judeorromances más conocidas. Este hecho, además, se fue acrecentando a medida que transcurrían los capítulos, lo que podría ofrecer una idea aproximada del agotamiento de fray Luis antes comentado. Pero de ello trataré en otro lugar.

Sin embargo, el entorno luisiano en los años de composición del Cantar de los Cantares fue bien distinto. Escrita mucho antes y sin la más mínima conciencia del mal trago que se le avecinaba, su obra debió de importarle lo suficiente como para rehacerla en varias ocasiones. El ambiente que por entonces respiraba fray Luis lo facilitó, sin duda. Con ello, no quiero decir que los distintos testimonios que se conservan de su comentario salieran de su puño y letra, pero sí que el humanista conquense rehizo en más de una ocasión aquella obra y que es posible que esas variantes legítimas y originales, junto a otras producto de los amanuenses, se hayan transmitido a través de distintas copias hasta la actualidad. La existencia de al menos dos versiones originadas por el propio fray Luis parece innegable.

En cualquier caso, fray Luis de León debió de tener con casi toda

18. José de Sigüenza, Vida de san Gerónimo, lib. V, discurso III, ed. D. Antonio Pérez Dubrull, Madrid, Imprenta de la Esperanza, 1853, p. 413. 
seguridad entre sus manos una Biblia judeorromance cuando se dispuso a elaborar su comentario, hoy probablemente perdida. Pese a esta casi segura y lamentable pérdida, las similitudes que se comprueban entre su traducción y el manuscrito 10288 de la Biblioteca Nacional de Madrid son bastante llamativas ${ }^{19}$. Este códice mantiene ciertas relaciones con los manuscritos E4 y E5 escurialenses, ya que comparten el romanceamiento de algunos libros bíblicos. Con ellos suele coincidir la versión de fray Luis, como habrá oportunidad de comprobar, por lo que considero más que probable que el agustino consultara en su momento una versión afín a la transmitida por los anteriores manuscritos o incluso, más difícilmente, de su misma familia.

Desde luego, pocos como él tuvieron conciencia inequívoca de que no había nadie mejor que los antiguos judíos de Sefarad, ya exiliados, para ofrecer el significado concreto de los términos hebreos; nadie como ellos para traducir de forma inmejorable la Biblia hebrea. Pero fray Luis no quiso convertirse en un mero copista y de ahí que reelaborara, personalizándola, la traducción judeomedieval que seguramente llegó a copiar. Este hecho explicaría, por otro lado, el controvertido asunto de las dos redacciones de su versión romance.

El siguiente cotejo, por tanto, pretende ofrecer sólo una simple muestra sobre la que cimentar esta más que posible teoría. La colación se ha desarrollado en cuatro apartados principales que, pese a encontrarse relacionados entre ellos, se han estructurado de forma independiente. Esta distribución permitirá incidir con mayor claridad y eficacia en el aspecto más relevante de cada apartado, cuyo contenido, de forma resumida, es el siguiente:

1) En la sección primera se expondrán ejemplos de coincidencias que relacionan la versión del humanista con las traducciones medievales que habían llevado a cabo los antiguos judíos de Sefarad. Se trata de un primer acercamiento y de una confrontación no definitiva, pero imprescindible para conectar la traducción de fray Luis con las versiones judeorromances. En cualquier caso, las semejanzas son a menudo asombrosas, tanto que muy difícilmente podrían sostenerse basándolas en la mera coincidencia.

2) El segundo apartado se destina a los ejemplos de doble redacción o, al menos, a casos donde uno de los testimonios conservados de la traducción del conquense siempre coincide con la versión judeorromance. Este aspecto podría ser índice de cambios producidos directamente por la mano del hebraísta salmantino, a la vista de la traducción medieval.

3) En el tercero se expondrán diversas traducciones de términos hebreos

19. En lo sucesivo se citará como $B N$, siguiendo la tradición actual. 
forjadas por fray Luis de León, distintas a las ofrecidas por las versiones judeorromances en cada caso, pero con las cuales vendría a coincidir en sus diversos comentos a cada versículo. Podría tratarse de un modo de recoger la traducción de los judíos medievales, sin que esto le impidiera al agustino ofrecer más tarde la suya propia.

4) Por último, en la cuarta sección, a modo de complemento, se expondrán algunos ejemplos de la versión del humanista, en los que las únicas diferencias respecto de las traducciones judeomedievales parecen responder a la simple modernización del léxico por parte del conquense.

\section{Ejemplos de Coincidencias: del azar a la certeza.}

Las semejanzas entre la versión de fray Luis de León y las traducciones bíblicas judeorromances son en ocasiones tan netas y asombrosas que casi podría descartarse la posibilidad de que nos halláramos ante simples coincidencias azarosas. Claro que esa cuestión supondría en principio aceptar un influjo constante que conllevaría necesariamente una indudable merma en la originalidad de la traducción del fraile agustino, que no todos estaríamos dispuestos a aceptar. En todo caso, este hecho no habría de verse como un menoscabo, antes al contrario.

Pocos como fray Luis, ya se ha dicho, supieron valorar y aprovechar la labor de los antiguos judíos criados al calor de las aljamas españolas; y mucho menos poner sus aciertos al servicio de aquellos que quisieron aprender la traducción del texto hebreo. El catedrático salmantino, por tanto, olvidando la reciedumbre de los tiempos y liberado de los absurdos recelos de ciertos teólogos, acudió a las fuentes, a los verdaderos sabios, para extraer de ellos su sabiduría y dejarla en las alas del viento. Su actuación, lejos de poderse considerar reprobable, resultaba más bien digna de encomio, máxime cuando las circunstancias no fueron ni mucho menos las más propicias.

Véanse ahora, de cualquier modo, algunos de los casos que corroboran las enormes analogías a las que se aludía con anterioridad. He de advertir, no obstante, que son muy pocas las ocasiones en que los distintos testimonios de la Exposición de fray Luis coinciden de forma completa. Por tanto, ciertos ejemplos que veremos ahora podrían ser igualmente estudiados en el segundo apartado, dedicado a los casos de doble redacción ${ }^{20}$.

20. Para las citas de las versiones medievales, utilizo mi edición de las biblias judeorromances, aún inédita. Saldrá publicada próximamente acompañada de un estudio sobre su proyección en el humanismo español. Las traducciones bíblicas empleadas en los siguientes cotejos son las citadas E3, E4, E5 y BN, más las conocidas Biblia de Alba (Alba), Biblia de 


\section{Cant 1, 3:}

Fray Luis:

$\mathrm{Al}$ olor de tus ungüentos buenos, ungüento derramado tu nombre. Por esso las doncellas te amaron. (L. 103)

$\mathrm{BN}$ : $\quad \mathrm{Al}$ olor de tus ungüentos buenos, ungüento vaziadizo es tu nombre. Por esso las doncellas te amaron ${ }^{21}$.

\section{Cant 2, 8:}

Fray Luis:

Voz de mi amado, helo, viene atravancando por los montes, saltando por los collados. (L. 138)

BN: La boz de mi amigo, helo éste do viene paseando por las sierras, saltando sobre los collados ${ }^{22}$.

\section{Cant 3, 1:}

Fray Luis:

En el mi lecho en las noches busqué al que ama mi alma; busquéle y no le hallé. (L. 146)

Alba: En el mi lecho en las noches busqué a aquel que la mi ánima ama; busquelo e non lo fallé.

Este mismo versículo posee una versión distinta en el comentario espiritual atribuido a fray Luis, coincidente con una de las biblias judeorromances:

Fray Luis:

E5:
Sobre mi cama en las noches busqué al que ama mi alma; busquélo, y no lo hallé. (L. 306)

Sobre mi cama en las noches busqué a aquel que amava la mi alma; busquelo en non lo fallé.

\section{Cant 3, 2}

Ferrara (Ferrara) y la contenida en el manuscrito CXXIV/1-2 de la Biblioteca Pública de Évora $(E V)$. Para la traducción romance de fray Luis, dado que resulta imprescindible el manejo de al menos dos testimonios para verificar los cambios producidos en su redacción, bien debidos al propio humanista, bien debido a los copistas, cito por la edición del manuscrito de Lisboa llevada a cabo por José María Becerra Hiraldo (véase n. 10), en cuyo caso el número de página viene precedido por la letra 'L', y por la edición de José Manuel Blecua (véase n. 9), en cuyo caso el número de página viene precedido por la letra ' $\mathrm{B}$ '.

21. Nótese que existe una mínima diferencia en la traducción derramado-vaziadizo. No obstante, en el comentario espiritual atribuido a fray Luis aparece en su lugar vaciado (ungüento vaziado es el tu nombre) con lo que la versión del humanista resulta exactamente la misma que la judeomedieval.

22. El adverbio «do» es una glosa sin correspondencia con el texto bíblico hebreo, introducida por el traductor judío. Resulta pues muy curioso que la versión de fray Luis editada por el padre Merino dijera asimismo: «helo do viene». Otra coincidencia más con las biblias judeorromances la aportan Alba y Ferrara, en cuyas traducciones se había optado por los términos montes y collados, al igual que en la versión de fray Luis de León. 
Fray Luis:

E3:
Levantarme he agora y cercaré por la ciudad, por los barrios y por las plazas, buscaré al que ama mi alma; busquele y no le hallé. (L. 148)

Levantarme he agora y arrodearé por la ciudad, por las calles y por las plazas, buscaré al que amó mi alma; busquelo e non lo fallé.

Hay que advertir además que en el cuerpo del comentario había subrayado el fraile agustino: «olvidando su condición y su temor, de noche, a solas, rodeé las calles y las plaças» ${ }^{23}$. Esta lectura coincidía ya plenamente con la versión judeorromance.

\section{Cant 3, 3}

Fray Luis:

Encontráronme las guardas que rondan la ciudad, ¿visteis por ventura al que ama mi alma? (L. 149)

E5: Falláronme las guardas las que rondavan la cibdat, ‘a aquel que ama mi alma avedes visto?

\section{3,11}

Fray Luis:

Salid y ved, hijas de Sion, al rey Salomón con la corona con que le coronó su madre en el día de su desposorio y en el día de la alegría de su corazón ${ }^{24}$.

$\mathrm{BN}$ : Salid e ved, o fijas de Sion, al rey Salamón con la corona de que lo coronó su madre en el día de su boda, e en el día del alegría de su coraçón.

La mínima diferencia léxica que se observaba entre ambas versiones (desposorio-boda), se desvanecía con la simple muestra de otros romanceamientos. Así, la famosa Biblia de Alba traducía, con fray Luis: «en el día del su desposorio».

\section{Cant 4, 14}

Fray Luis:

Nardo y azafrán, canela y cinamomo con los demás árboles del encienso. Mirra y linaloe, con todos los principales olores. (L. 156)

23. Esta glosa se ha transmitido al menos en tres de los testimonios conservados: el manuscrito 109 del archivo de la Catedral de Palencia y los manuscritos 260 y 299 de la Biblioteca Pública de Toledo.

24. Así reza en la edición de José Manuel Blecua, p. 117. El manuscrito de Lisboa, en cambio, lee del mismo modo con la excepción del final del verso: «en el día del regocijo de su corazón» (L. 147). El cambio de vocablos por sinonimia (regocijo-alegría) es frecuente en la transmisión de los manuscritos. Sin embargo, el hecho de que el cambio produzca la igualdad con la versión judeorromance quizá no sea casual y sí provocado por el propio humanista. Pero de este tipo de cambios trataré en el próximo apartado. 
Ferrara: $\quad$ Nardo e azafrán, canela e cinamomo con todos los árboles de encienso. Mirra e aloes, con todas las principales especias.

La curiosísima traducción de este versículo podría esgrimirse como inmejorable ejemplo del segundo apartado, teniendo en cuenta la variante que poseía el manuscrito editado por J. Manuel Blecua. En él, la lectura con los demás árboles del encienso, quedaba transformada en con los demás árboles del Líbano (B. 133). Esta variante, en sí misma, no sería demasiado llamativa si no fuera por el hecho de que también las versiones judeorromances se habían encargado de transmitir, junto a la traducción con todos los árboles de encienso, la misma lectura que el agustino. Entre otros manuscritos, el citado $B N$ leía con todos los árboles del Líbano.

La variante que venía a separar la traducción de las biblias medievales procedía del distinto entendimiento que hicieron sus autores del término original hebreo לבונה l'bônāh, cuya correcta traducción era "incienso». Sin embargo, por su proximidad fonética y formal, algunas versiones לבנון judeorromances derivaron aquella voz hebrea del parecido vocablo l’bānôn, es decir, "Líbano». De ahí su diversa traducción, ya incienso, ya Líbano. Otra cosa sería averiguar si la confusión, o cambio consciente, en el comentario del maestro salmantino, es decir, su lectura «Líbano» por «incienso», procedía o no de aquellas versiones bíblicas con las que por cierto coincidía.

En principio, que las versiones sefardíes transmitiesen dos interpretaciones distintas de un mismo término hebreo se explicaba por el hecho de que pertenecieran a diferentes traductores. Sin embargo, sería difícil de justificar que un mismo intérprete, en este caso fray Luis, hubiese llegado a traducir de forma desigual un mismo vocablo, sin que además lo fundamentase de algún modo como sí había hecho en otras ocasiones. Así pues, el cambio de «incienso» a «Líbano» originado en el comentario del teólogo salmantino no parecía responder sino a la utilización de las versiones sefardíes por parte del humanista y al olvido de su primitiva traducción.

\section{Cant 4, 15}

Fray Luis:

$\mathrm{BN}$ :
Fuente de huertos, pozo de aguas vivas que manan del Líbano. (L. 319)

Fuente de huertos, pozo de aguas vivas que destellan del Líbano ${ }^{25}$.

25. Según E3 o Ferrara, «manantes del Líbano», en coincidencia léxica con fray Luis. 


\section{BULLETIN HISPANIQUE}

\section{Cant 5, 1}

Fray Luis:

Vine a mi huerto, hermana mía, esposa, cogí mi mirra y mis olores, comí mi panal con la miel mía, beví el mi vino y la mi leche. Comed, compañeros, beved y embriagadvos, amigos. (L. 176).

Alba:

Vine al mi huerto, la mi hermana, novia, cogí mi mirra con el mi aromático, comí el mi panar con la mi miel, beví el mi vino con la mi leche. Comed amigos, beved e enbriagadvos, queridos ${ }^{26}$.

\section{Cant 5, 2}

Fray Luis:.

Yo duermo y el mi corazón vela. La voz de mi querido llama. Ábreme, hermana mía, compañera mía, paloma mía, perfecta mía, porque mi cabeza está llena de rocío y mis cabellos de las gotas de la noche. (L. 176)

Alba:

Yo duermo e mi corazón vela. La voz de mi querido pulsa. Ábreme, la mi hermana, la mi amiga, la mi paloma, la sin manzilla mía, que la mi cabeça llena es de rucío e las mis crines de las gotas de la noche.

En este último ejemplo, el término cabellos utilizado por fray Luis en la parte final del versículo, al que prácticamente quedaba reducida la disparidad entre ambas versiones, podría considerarse una mera modernización o mejora estilística del más arcaico crines. No obstante, en lugar de cabellos, la versión del Cantar incluida en los Nombres de Cristo vertía guedejas; un término ya empleado por la Biblia de Ferrara y por otras versiones medievales, como E5: que mi cabeça es llena de rocío, mis guedejas de gotas de noche. Asimismo, dentro de estas analogías, cabía añadir aún otra sugerente similitud, relacionada una vez más con $B N$, cuya enumeración resultaba ser igual a la esgrimida por el humanista: hermana mía, compañera mía, paloma mía, perfecta mía.

\section{Cant 5, 8}

Fray Luis:

E5:
Yo os conjuro, hijas de Jerusalem, que si halláredes a mi querido, me lo hagáis saber que soy enferma de amores. (L. 176)

Conjúrovos, hijas de Jerusalem, si halláredes al mi querido, que le denunciedes en cómo só enferma de amores.

26. $B N$ se acerca aún más en su parte final a la traducción de fray Luis: «comed, compañeros, beved e enbeudadvos, amigos». Por su parte, $E 4$ coincide con el agustino en la traducción del verbo: «embriagadvos». 


\section{Cant 6, 1}

Fray Luis:

E3:

Fray Luis:

E4-BN:

Fray Luis:

BN:

Alba:

Fray Luis:

E3:

¿A Dónde se fue el tu amado, o hermosa entre las mugeres?, ¿Dónde se bolvió el tu querido e buscarle hemos contigo? (L. 177)

¿A dónde fue tu enamorado, la fermosa en las mujeres? ¿A dónde bolvió tu enamorado e buscarlo hemos contigo?

\section{Cant 6, 4-8}

Hermosa eres, amiga mía, como Thirsá, bella como Jerusalem, terrible como los escuadrones [...]. Sesenta son las reinas y ochenta las concubinas y doncellas sin cuento. (L. 195)

Fermosa eres, amiga mía, como Tirsá, suave como Jerusalem, terrible como los pendones [...]. Sesenta son las reinas e ochenta barraganas, e donzellas sin cuenta.

\section{Cant 7, 8}

Esta tu estatura semejante es a la palma y tus pechos a los racimos. Dixe: yo subiré en la palma, asiré sus ramos y serán tus pechos como los racimos de la vid y el olor de tu nariz como de las mançanas. (L. 372).

Esta tu altura semeja palma e tus tetas a los razimos. Dixe: subiré en la palma, travaré de sus ramas, e sean agora tus tetas como los razimos de la vid e el olor de tus narizes como las mançanas.

El tu estado a palma asemeja e las tus tetas a razimos. Yo dixe: sobiré en la palma, asiré en las ramas del su fructo e serán las tus tetas segund razimos de vid e el olor de tu nariz como mançanas.

\section{Cant 7, 10}

El tu paladar como vino bueno, que va a mi amigo a las derechuras, hace hablar los labios de dormientes. (L. 219)

E tu paladar como el vino bueno, que anda a mi enamorado por las venas, faze fablar los beços de los que duermen.

En esta ocasión, la Biblia romance se distancia de la versión del humanista en la difícil traducción término hebreo למשרים l'mešarîm (a las derechuras, según la traslación de fray Luis). La versión medieval, por su parte, 
parecía haber traducido por el sentido (por las venas), aunque no faltaron romanceamientos que se acercaran a la traducción del afamado hebraísta: yente a mi amigo en derechedumbres ( $B N)$; al su talante derechamente (E5), o andán a mi querido en derechedades (Ferrara). Por otra parte, la traducción «labios», no era sino una modernización de la voz medieval «beços». De hecho, una versión más tardía como era la de Ferrara optaría ya por el vocablo «labios» (en verdad, «labrios»).

\section{Cant 8,1}

Fray Luis:

¿Quién te me dará como hermano mío, que mamases los pechos de mi madre? Hallar te ía fuera, besar te ía e nadie me despreciaría. Coger te ía, meter te ía en casa de mi madre; enseñaríasme; daríate a beber del vino adobado y del mosto de las granadas mías ${ }^{27}$.

E3:

¿Quién te me diese por hermano mío, que mamaras las tetas de mi madre? Fallar te ía en la calle, besar te ía, aun non despreciarían a mí. Guiar te ía e traer te ía a casa de mi madre; abesar m'ías e dar te ía a beber del vino confacionado, del mosto de mi granada.

\section{Cant 8,12}

Fray Luis:

La viña mía que es mía delante mí; mil para ti, Salomón, y ducientos para los que guardan su fruto. (L. 226)

$\mathrm{BN}$ :

La mi viña que es mía es delante mí. Los mil son tuyos, Salamón, e dozientos a los que guardan su fruto ${ }^{28}$.

\section{Ejemplos de dos redacciones.}

En la mayoría de las ocasiones, los testimonios que se poseen de la Exposición literal de fray Luis no suelen coincidir entre ellos de una manera exacta. A menudo, las diferencias atañen sólo a algunos términos concretos, pero importantes en la traducción. En otras ocasiones, las diferencias no

27. La traducción del pasaje no posee unanimidad y son varias las variantes que pueden observarse en los distintos manuscritos. En ellos se nota la mano de los copistas y la difícil transmisión del versículo, en el que no faltan correcciones, omisiones, errores, etc. El versículo que se presenta es una reconstrucción basada en el cotejo de distintos testimonios que pretende acercarse lo más posible al original escrito por fray Luis.

28. En la versión $E 3$ se lee: «los mil son para ti», es decir, tal y como traduciría siglos más tarde fray Luis de León. 
proceden de distintos testimonios, sino de un mismo comentario. Como se sabe, el agustino colocó al frente de cada capítulo la traducción de todos y cada uno de los versículos de que aquél se componía. Luego, en el comentario independiente a cada versículo, volvían a aparecer encabezando su respectivas glosas. Pues bien, no faltaron los casos en que la versión capitular no coincidía con la traducción versicular ${ }^{29}$.

Este fenómeno fue considerado por Juan José Sendín como una forma de crear literatura, o mejor dicho, una forma de agotar los significados que proporcionaban los términos hebreos. De ahí que lejos de estimarse como posibles olvidos respecto de las traducciones ya ofrecidas al comienzo de cada capítulo, estas nuevas versiones fuesen una forma de creación plenamente consciente.

Sin embargo, tampoco sería descabellado considerar que las diversas versiones de un mismo versículo, ya procedieran de un solo comentario, ya de distintos, pudieran emanar de una consulta directa de las traducciones bíblicas judeorromances por parte del conquense, máxime cuando una de sus versiones siempre venía a coincidir con éstas. De hecho, es bastante probable que fray Luis personalizara las traducciones que había hallado en los romanceamientos, pero que, al mismo tiempo, no se resistiera a ofrecer la lectura proporcionada por los judíos sefardíes, lo que considero una muestra incuestionable de la clarividencia del agustino.

Fray Luis de León -ya lo apuntaba anteriormente-, estaba despojado de los prejuicios que sí llegaron a apoderarse de grandes teólogos como Melchor Cano o Alfonso de Castro ${ }^{30}$. El maestro salmantino era lo suficientemente cabal como para darse cuenta de que pocos como aquellos judíos estaban

29. Ambas expresiones fueron acuñadas por Juan José Sendín Vinagre para distinguir precisamente la traducción que encabezaba cada capítulo y la que aparecía al frente del comentario de cada versículo. Véase su artículo «Las exposiciones del Maestro León, o cómo se hace literatura a propósito de las Letras Sagradas», en Fray Luis de León. Historia, Humanismo y Letras, ed. cit., p. 701-707.

30. Para Melchor Cano, las mayores herejías de su época derivaron de las biblias romances y de su lectura por parte del inculto pueblo. Así lo afirmó con rotundidad en la censura que llevó a cabo del Comentario al Catecismo Christiano de Bartolomé Carranza. Cf. Melchor Cano, en Conquenses Ilustres II, Madrid, Imprenta del Colegio Nacional de Sordo-Mudos y de Ciegos, 1871, p. 536-542. No menos crítico con la traducción de la sagrada Escritura en lenguas vulgares fue Alfonso de Castro. Véanse sus obras Adversus omnes haereses y De iusta haereticorum punitione, en Opera Alfonsi a Castro Zamorensis..., Madrid, Typographia Blasii Roman, 1783, p. 40-42 y 219-226. Un resumen de sus opiniones, junto a las críticas de otros teólogos como Domingo de Soto, Martín Pérez de Ayala o Alejo Venegas puede consultarse en Sergio Fernández López, Lectura y Prohibición de la Biblia..., ed. cit., p. 225-265. 
capacitados para traducir al romance un texto bíblico redactado en su segunda lengua materna, el hebreo. Por ello, no dudo de que el humanista acompañara su propia versión de la traducción romance que había podido copiar de cualquier manuscrito, de los pocos que aún quedaban dispersos por las bibliotecas nobiliarias, conventuales y universitarias.

Así pues, el hecho de que una de las dos redacciones de cada pasaje coincidiera siempre con alguna versión judeorromance constituía un fenómeno que no debería de juzgarse a la ligera y que podría ser la prueba de que fray Luis llegó a utilizar las traducciones de los judíos medievales. Los siguientes ejemplos, al menos, no oponen la más mínima resistencia y parecen muestra inequívoca del asunto.

En este apartado, por tanto, se expondrán siempre dos testimonios de un mismo pasaje no coincidentes entre ellos, aunque pertenecientes ambos a la traducción de fray Luis, seguidos de una versión judeorromance con la que siempre convendrá uno de aquéllos.

Cant 1,10

Fray Luis: $\quad$ Lindas tus mexillas en las perlas [...] (B. 57)

Fray Luis: $\quad$ Lindas tus mexillas con los cercillos [...] (L. 104)

BN: $\quad$ Adonáronse tus mexillas con los cercillos $[\ldots]^{31}$

Cant 2, 3

Fray Luis: $\quad$ [...] Y su fruto es dulce a mi garganta. (B. 89)

Fray Luis: $\quad$ [...] Y su fruto es dulce a mi paladar. (L. 285).

BN: $\quad[\ldots]$ E el su fruto dulce es a mi paladar.

Es probable que la elección del término paladar que ilustraba el manuscrito de Lisboa no tuviese otro origen que el deseo de fray Luis de verter con mayor propiedad el significado de la palabra original hebrea ח 'gusto, paladar'. De este modo, además, su versión quedaba desvinculada de cualquier posible relación con la Vulgata, cuya traducción había sido, en efecto, guttur 'garganta'. No obstante, el hecho de que el cambio de garganta

31. Tanto la traducción de este versículo como la del siguiente (Cant 1, 11), no encuentran unanimidad en ninguno de los testimonios de la Exposición, pero casualmente todos ellos transmiten la misma traducción que las biblias judeorromances. Así, se encuentran versiones como «joyas de oro te haremos» (coincidente con Ferrara), o "çarcillos de oro de faremos» (coincidente con E4). Las coincidencias se encuentran incluso en la glosa de los versículos, donde comenta fray Luis: «bellas son tus mejillas como las piedras puestas en orden; esto es descripción de las arracadas que las mugeres cuelgan de las orejas». Precisamente, tanto Alba como E3 traducen: «arracadas de oro te faremos». 
a paladar llegara a producir la igualdad con la traslación sefardí posibilitaba que el origen de tal mudanza estuviese ciertamente en la utilización de las biblias judeorromances por parte del teólogo salamantino.

\section{Cant 3, 6}

Fray Luis: Quién es esta que sube del desierto, como columnas de humo, de oloroso perfume de mirra y encienso y todos los polvos del maestro de los olores (B. 116)

Ferrara: Quién es esta subién del desierto, como colunas de humo, safumada de mirra e encienso, de todo polvo de especiero.

En este caso, la versión del humanista coincidía con la traducción bíblica de Ferrara en la declaración de la expresión hebrea תמרות עשן 'columnas de humo'. Sin embargo, este giro podía interpretarse de modo distinto según la lengua original ${ }^{32}$. De ahí que otros testimonios de la Exposición de fray Luis hubieran transmitido una traducción diferente del pasaje:

Fray Luis: Quién es esta que sube del desierto como palmas de humo, perfumada con mirra y encienso y con todos los polvos del ungüentario. (L. 310)

BN: Quién es esta subiente del desierto como palmas de fumo, sahumada con almizque e encienso e con todo polvo de especiero.

Los cambios que manifestaba esta nueva versión no sólo eran llamativos en sí mismos (palmas por columnas, perfumada por de oloroso perfume, ungüentario por maestro de los olores), sino también, y sobre todo, en relación con la traducción judeomedieval, puesto que todos ellos se hallaban en cierto modo en la antigua versión sefardí.

Cant 4,2

Fray Luis:

tus dientes como hato de ovejas tresquiladas que vienen de vañarse; las quales todas paren de dos en dos y ninguna entre ellas ay vazía. (L. 155)

32. En verdad, la expresión "columnas de humo» no respondía literalmente a la traducción del texto hebreo, sino a la interpretación que de dichos términos habían ofrecido los exégetas judíos. Entre otros, Abraham ibn 'Ezra' fue uno de los encargados de otorgarles tal significado, al interpretarlas como עמודים עשן esto era, 'columnas de humo'. La traducción de fray Luis, por tanto, podía provenir ya directamente de la exégesis hebrea, ya de las biblias judeorromances. 
Así rezaba la versión de fray Luis en gran parte de los manuscritos. Sin embargo, algunos de ellos, que estaban evidentemente emparentados ${ }^{33}$, tradujeron el versículo de forma bien distinta y muy semejante a las biblias judeorromances:

Fray Luis:

tus dientes como rebaño de ovejas tresquiladas que salen de vañarse, todas ellas parideras con sus crías, que no hay machorra en ellas. (B. 131)

E5: tus dientes así como el rebaño de las ovejas que suben del lavadero, son todas parideras, que machorra non ay en ellas ${ }^{34}$.

\title{
Cant 4,8
}

Fray Luis:

Conmigo del Líbano, Esposa, conmigo del Líbano te vendrás; y serás coronada desde la cumbre de Amaná, de la cumbre de Senir y Hermón, de las cuebas de los leones y de los montes de las onzas. (B. 132)

Junto a esta versión, la mayor parte de los manuscritos que transmitieron la Exposición literal diferían tanto en los verbos como en la última parte del versículo. He aquí los cambios más significativos, señalados en cursiva, seguidos de la correspondiente biblia judeorromance con la cual coincidía esta nueva traslación:

Fray Luis:

\author{
Conmigo del Líbano, Esposa, conmigo del Líbano \\ vernás; mirarás desde la cumbre de Amaná, de la cum- \\ bre de Senir y Hermón, de las moradas de los leones y \\ de los montes de los pardos. (L. 318-19)
}

33. Se trata de los dos citados manuscritos de la Biblioteca Pública de Toledo y el manuscrito que se custodia en el Archivo de la Catedral de Palencia.

34. Estas semejanzas también eran extensibles a la glosa del pasaje, en la cual habría de afirmar el maestro León: «donde dezimos tresquiladas, la palabra hebrea es [...] y así quiere decir [...] del todo iguales; que declara la igualdad de los dientes que he dicho, que se compara el estar juntos y ser menudos, en decir como un hato de ovejas, que van asi siempre juntas». Precisamente esta glosa venía a coincidir con la traducción de otras biblias judeorromances: «tus dientes como la manada de las iguales, que suben de lavarse, que son todas juntas". Relacionado con este versículo se encontraba uno posterior (Cant 6, 6), de semejante traducción y que quedó del siguiente modo en el comentario del humanista: «Tus dientes como hataxo de ovejas que suben del lavadero, las quales todas paren de dos en dos, y no hay estéril en ellas». La parte final de este pasaje tampoco estuvo exenta de variante: «todas paren de dos en dos y ninguna en ellas deshijada». ¿ Habría que pensar de nuevo en la casualidad, cuando al cotejar las versiones del humanista con las citadas biblias medievales observamos coincidencias como "que suben del lavadero» (E5), o «deshijada no hay en ellas» (BNy Ferrara)? 
E3:

Conmigo del Labanón, novia, conmigo del Labanón vernás, mirarás del cabo de Amaná, del cabo de Sanir e de Hermón, de las moradas de los leones e de los montes de las onças.

Sería difícil de creer que tanta coincidencia fuera fruto de la casualidad; pues, si bien el término cumbre podía estimarse una modernización del arcaico cabo, sin que necesariamente hubiera que poner en relación ambas traducciones, la semejanza en los verbos (vernás y mirarás) y en el léxico empleado (moradas, leones, montes, onças), decantaba nítidamente la balanza hacia una segura conexión. Pero aún había más; otra de las traducciones del agustino ofrecía la misma interpretación que otra de las versiones judeorromances:

Fray Luis:

Alba:
[...] otearás desde la cumbre de Amaná, de la cumbre de Senir y Hermón, de las cuebas de los leones y de los montes de los pardos. (L. 155)

[...] atalearás del cabo de Amaná, del cabo de Senir e Hermón, de las cuebas de los leones; de los montes de los pardos.

Una vez más, si el verbo otearás, transmitido por algunos de los testimonios del comentario luisiano, parecía una simple modernización del medieval atalearás, la igualdad que se observaba en el resto del versículo (cuebas, leones, montes, pardos), no hacía sino relacionar esta nueva versión bíblica con la del maestro salmantino.

\section{Cant 6, 11}

Fray Luis: $\quad$ Al huerto de los nogales descendí, a ver los frutos de los valles, y si florecía la vid y si florecían los granados. (B. 208)

Alba:

Al huerto de los nogales descendí, a ver las frutas del valle, a ver si florecen las viñas, si apuntan las granadas.

Tanto la traducción del conquense como la judeorromance estaban estrechamente unidas. Pero no fue ésta la única versión del pasaje. A la anterior se sumaban otras dos redacciones que, una vez más, concertaban con las antiguas versiones sefardíes. La primera de ellas decía:

Fray Luis:

$\mathrm{BN}$ :
Al huerto de los nuezes descendí, para ver los frutos de los valles, y ver si florecía la vid y si florecían los granados. (L. 359)

A la huerta de las nuezes descendí, para ver las frutas del arroyo, para ver si floreció la vid e si florecieron los granados. 
Mientras la segunda añadía una nueva traducción al comienzo del versículo:

Fray Luis:

E3:

Frray Luis:

$\mathrm{BN}$ :
Al huerto del nogal descendí, por ver los fructos [...]. (L. 195)

A la huerta del nogal descendí, a ver los frutales $[\ldots]^{35}$.

\section{Cant 7, 2}

Los cercos de tus muslos como axorcas, labradas de mano de oficial. (B. 215)

Los cercos de tus ancas como ornamentos, fechura de mano de maestro.

La traducción de fray Luis parece en una aproximación inicial algo alejada de la versión romance. Sin embargo, la transformación que había de sufrir en el resto de los testimonios la iba a acercar de forma manifiesta a los romanceamientos medievales. Con todo, ambas versiones se hallaban bastante más unidas de lo que a simple vista podía parecer.

Dejando a un lado la parte final del versículo, en la que me detendré seguidamente, en el resto sólo se contabilizaban dos diferencias. La primera de ellas respondía a la lógica modernización del término medieval anca, sustituido por su correspondiente actual muslo. La segunda, quizá algo más significativa, afectaba al vocablo ornamentos, traducido como axorcas en la versión de fray Luis. Pero esta traslación no era desconocida entre los judíos. De hecho, una Biblia como Ferrara, utilizada con frecuencia por el agustino, había traducido tus ancas como axorcas, por lo que no podía descartarse que fray Luis lo hubiera tomado prestado de aquella versión, que había seguido además en tantas ocasiones.

Pero había más; tampoco en este caso había sido aquélla la única redacción, como ya se dijo; la parte final del versículo adquirió diversas formas, ya fuesen propiciadas por el propio humanista, ya por la transmisión de las copias. Lo cierto era que aquellas nuevas versiones venían a coincidir de nuevo con las traducciones judeorromances. La versión anteriormente expuesta: labradas

35. No es extraño que el comienzo del versículo poseyera distintas redacciones desde el punto de vista del hebreo. El término אגוז ěgôz no tenía una fácil traducción. El exégeta sefardí Abraham ibn Ezra remitiría para su significado a la literatura rabínica, donde en efecto aparecería traducido como nuez, pero también nogal. De ahí quizás estas distintas versiones. En todo caso, la coincidencia de las traducciones del humanista con las biblias judeorromances las colocaban en un mismo plano. 
de mano de oficial, se tornaba en labradas de mano de maestro (B. 220), obra de mano de maestro (L. 372) y hechas por mano de maestro (L. 221). En este sentido, las biblias judeorromances tradujeron a su vez el versículo de la misma forma: labradas de mano de maestro (Alba), obra de mano de maestro (Ferrara), y fechas de mano de maestro (Ev).

\section{Cant 8,7}

Fray Luis: $\quad$ Muchas aguas no pueden apagar el amor, ni los ríos lo pueden anegar. (B.246)

E5: Muchas aguas non pueden apagar el amorío, nin los ríos lo pueden amatar.

El único aspecto diferenciador entre ambas traducciones concernía al último verbo (anegar-amatar). Pero esta mínima desavenencia desaparecía en gran parte de los testimonios que se han conservado del comentario luisiano, en los que el fraile de san Agustín tradujo precisamente: ni los rios lo pueden amatar (L. 226).

\section{Ejemplos concretados o rectificados en el cuerpo del comentario ${ }^{36}$.}

Los dos apartados anteriores mostraban con cierto grado de seguridad que la versión del humanista y las judeomedievales se encontraban insertas en una misma tradición. Sin embargo, aquella línea tradicional sufrió una terrible ruptura con la definitiva expulsión de los sefardíes, que acabó irremediablemente con una brillante y pródiga etapa de traducciones bíblico-romances que se había mantenido durante algunos siglos. Así pues, las múltiples semejanzas que podían hallarse entre la versión medieval y la renacentista de fray Luis, una vez rota aquella línea, sólo podían explicarse como fruto de la recuperación y consulta directa de aquellas antiguas traducciones. Éstas volvían a salir a la palestra tras caer en el olvido, casi un siglo después de iniciada la diáspora.

Por tanto, y dicho de otro modo, si aquellas claras concomitancias no podían explicarse históricamente como un producto de la convivencia entre judíos y cristianos que ya había quedado en el olvido, es decir, como una influencia directa y tradicional, la única solución posible pasaba por la consulta de las pocas traducciones bíblicas que se habían salvado de las llamas y que tanto fray Luis, como otros humanistas, llegaron a conocer. En

36. Esta versión que aparece en ocasiones en medio de la glosa fue bautizada por Juan José Sendín Vinagre como «versión discontinua». Cf. Art. cit., p. 704. 
definitiva, el catedrático salmantino debió de tener entre sus manos alguno de aquellos romanceamientos cuando decidió dar forma a su Exposición literal del Cantar de los Cantares.

El presente apartado pretende corroborar esta misma posibilidad, cada vez más manifiesta por otro lado. La versión del agustino, desde luego, nunca perdió de vista la traducción ofrecida por las antiguas biblias judeorromances, si bien es cierto que en ocasiones sí podía observarse un cierto alejamiento de aquéllas. Este fenómeno fue explicado con anterioridad como un posible intento de personalización de las versiones consultadas. Sin embargo, ni tan siquiera en estos casos se perdía el rastro de la traducciones judeorromances, ya que, cuando las traducciones de la Exposición llamadas 'versicular' y 'capitular' no casaban del todo con las biblias romances, las coincidencias con estas últimas aparecían en los comentos de cada uno de aquellos versículos. La presencia de las traducciones judeomedievales parecía, pues, innegable. De otro modo, habría de explicarse aquel fenómeno como un proceso continuado de casualidades que difícilmente podría sostenerse. Sirvan como botón de muestra los siguientes ejemplos:

Cant 1,12

$\begin{array}{ll}\text { Fray Luis: } & \text { Cuando estaba el rey en su reposo. (B. 57) } \\ \text { Ferrara: } & \text { Mientras que el rey en su rescobdo [recobdadero (E5)] } \\ \text { Glosa: } & \text { La palabra hebrea, que es mecibo, quiere decir } \\ & \text { recostamiento [otros testimonios traen reclinado o re- } \\ & \text { clinación] (B. 52) }{ }^{37} .\end{array}$

Cant 2, 15

Fray Luis:

Prendedme las raposas [...] destruidoras de viñas y nuestra viña está en flor. (B. 111)

Ferrara: $\quad$ Travad a nós raposas [...] dañantes vińas, y nuestras viñas en cierne.

Glosa: $\quad$ Porque dixo que su viña estaba en cierne. (B. 112).

37. El término rescobdo o rescobdadero significa precisamente 'triclinio, reclinatorio'. Proviene seguramente del latín recubitum 'recostarse, apoyarse con el codo', y se trata de un vocablo propiamente judeoespańol. Vid. M. Gaspar Remiro, «Vocablos y frases del judeoespañol», BRAE, 5, 1918, p. 358-359. M. Alvar también recoge el significado del verbo rescobdar como «acodarse, apoyarse con el codo, reclinarse». El ladino, judeo-español calco, Madrid, BRAH, 2001, p. 274-75. Por tanto, junto a la probable influencia de las biblias judeorromances, podría hablarse de una modernización, o mejor, castellanización, del término por parte de fray Luis. 


\section{EL CANTAR DE LOS CANTARES DE FRAY LUIS DE LEÓN}

\section{Cant 2, 17}

Fray Luis:

Ferrara:

Glosa:

Fray Luis:

$\mathrm{BN}$ :

Glosa:

Fray Luis:

$\mathrm{BN}$ :

Glosa:

Fray Luis:

Ferrara:

Glosa:

Fray Luis:

Ferrara:

BN:
Sei semejante, amado mío, a la cabra o al corço sobre los montes de Bather. (L. 145)

Semeja a ti, mi querido, a corço o enodio de los ciervos sobre montes de división.

Bather quiere decir división. (L. 146) ${ }^{38}$

\section{Cant 3, 2}

Levantarme he agora y cercaré [...] por las plaças y lugares anchos. (L. 146)

Levantar me he agora e rodearé [...] por las calles e por las plaças.

De noche, a solas, rodeé las calles y las plaças. (L. 148) ${ }^{39}$.

\section{Cant 3, 6}

Quién es esta que sube del desierto como columnas de humo. (L. 146)

Quién es esta subiente del desierto como palma de fumo.

El hebreo dize palma de humo. (L. 313)

\section{Cant 3, 10}

[...] en medio dél, asentó el amor de las hijas de Jerusalem. (L. 306)

[...] su medio, abrasado de amor por las hijas de Jerusalem.

En el hebreo parece decir: abrasado por las hijas de Jerusalem. (L. 313)

\section{Cant 4,1}

Tu cabello como un rebaño de cabras que se levantan del monte Galaad. (L. 159)

Tu cabello como rebaño de las cabras que se pelan de monte de Gilhad.

Tu cabello como la manada de las cabras que se peinaron de la sierra de Galaad.

38. Una de las pocas biblias romances conservadas lee precisamente "montes de Bather» $(B N)$ con la que la versión del humanista coincide incluso en el vocalismo. No obstante, otros testimonios de su comentario, así como otras biblias judeorromances, leían de forma más correcta, Bether. No puede descartarse por tanto que el agustino hubiera tenido entre sus manos un manuscrito de la familia de $B N$, o cuya lectura hubiera sido, como en éste, montes de Bater.

39. Tanto la traducción de fray Luis como su glosa pueden consultarse en la página citada. No son lecturas, sin embargo, del manuscrito 2846 de Lisboa, sino de los manuscritos 260 y 299 de la Biblioteca Pública de Toledo, que aparecen como variantes en la edición anterior. 
Glosa:

Donde [...] dezimos se levantan, en el hebreo dice se peinan o pelan. (L. 161)

\section{Cant 5,7}

Fray Luis:

Halláronme las guardas [...], tomáronme mi manto de sobre mí. (L. 176)

E4:

Glosa:

Falláronme las guardas [...], levaron mi mantellina de sobre mí.

Dice $[. .$.$] que le quitaron el manto o mantellina con$ que se cubría. (L. 185)

\section{Cant 5, 12}

Fray Luis:

Sus ojos como los de palomas [...] bañadas con leche junto a la llenura. (B. 161)

E3:

Sus ojos como palomas [...] lavadas con leche, asentadas sobre fenchimiento.

Glosa:

Aquella palabra מלאת [...] significa llenura o henchimiento (B. 182) ${ }^{40}$

\section{Cant 5, 15}

Fray Luis:

El su vientre, blanco diente cercado de zafiros.

(L. 177)

E4:

El su vientre, luzio marfil cercado de çafires

Glosa:

Blanco diente, esto es, de marfil. (L. 192)

\section{Cant 5, 16}

Fray Luis: $\quad$ El su semblante como el del Líbano, erguido como los cedros. (B. 161)

E4:

La su vista como el Líbano, escogido como los cedros

Glosa:

Donde decimos erguido, la palabra hebrea es בתור bathur, que quiere decir escogido.

(B. 187-88).

\section{Cant 7, 1}

Fray Luis:

Qué lindos son tus pies [...] hija de príncipe. (B. 217)

E4:

Quánto se afermosyguaron tus pies [...] fija del liberal.

40. En el comentario espiritual atribuido a fray Luis, el agustino tradujo de modo distinto la parte final del versículo: «Sus ojos como los de palomas [...] con leche lavadas, asentadas sobre lo lleno» (L. 340). Así lo había traducido E5: «Los sus ojos de palomos [...] lavados con la leche e asentados sobre lleno". 
Glosa:

En hebreo se llama nadib, que es decir el noble, el liberal. (B. 218$)^{41}$.

\section{Cant 8,6}

Fray Luis:

El amor es fuerte como la muerte, duro como el infierno los zelos. (B. 246)

Ferrara: porque fuerte como la muerte el amor; duro como fuessa, zelo.

Glosa: Por el vocablo infierno entendemos sepulcro. (B. 268)

\section{Cant 8,6}

Fray Luis:

Las sus brasas, brasas del fuego de Dios. (L. 226)

Ferrara:

Las sus brasas, brasas de fuego, llama fuerte.

Glosa:

donde dice llamas de Dios declaramos recia y fuerte llama. (L. 237)

\section{Ejemplos de modernización.}

Por último, he querido añadir algunos otros pasajes donde la traducción del humanista concertaba de igual forma con las biblias judeorromances, pero en los que podía notarse la utilización de un léxico más moderno por parte de fray Luis. No obstante, en las traducciones humanísticas del Cantar de los Cantares siempre se había dejado notar la utilización de un léxico bastante arcaico.

Algunos investigadores, no faltos de razón, anotaron la analogía de este libro bíblico con el mundo pastoril, y el referente de la poesía de tipo popular como contexto y vehículo de expresión más adecuados para el desarrollo de su tema central: el amor entre dos pastores. De modo que el léxico arcaico que rezumaba de aquellos cantares bíblicos en romance respondía al intento de imitar el lenguaje sencillo y rudo de los pastores ${ }^{42}$.

41. Poco después añadía el conquense otro posible significado: hija del noble y del franco (B. 219). También este último significado aparecía en las biblias judeorromances, como demostraba la versión E3 escurialense: "Quánto son fermosos tus pies [...] la compaña franca»

42. Vid. Luis Gómez Canseco y Valentín Núñez Rivera, Arias Montano y el Cantar de los Cantares. Estudio y edición de la Paráfrasis en modo pastoril, Kassel, Reichemberger, 2001, p. 65-68. Sobre este asunto pueden consultarse, también de los mismos autores, otros dos interesantísimos estudios: Valentín Núñez Rivera, «De égloga a lo divino y bucólica sacra. A propósito del Cantar de los Cantares en la poesía áurea», en La Égloga, ed. Begoña López Bueno, Sevilla, Universidad de Sevilla, 2002, p. 207-263; y Luis Gómez Canseco, «Notas para un itinerario humanístico del Cantar de los Cantares en el mundo hispánico», en Grafías del imaginario. Representaciones culturales en España y América (siglos XVI-XVIII), eds. Carlos Alberto González y Enriqueta Vila Vilar, México, Fondo de Cultura Económica, 2002, 
Pero a esta plausible explicación podía añadirse aún otra: aquellas expresiones arcaizantes procedían no de la creación de un léxico propicio para ser puesto en boca de personajes campestres, sino de la consulta de aquellas biblias medievales cuyo léxico les era natural por su antigüedad. Por tanto, sólo en los casos en los que los términos podían resultar incomprensibles para el lector de la época por su desuso y primitivismo se optó por la modernización. Algunos de ellos ya se han ido apuntando en apartados precedentes; he aquí algunos otros:

Cant 1,12

Fray Luis:

Ferrara:

Fray Luis:

E3:
Quando el rey en su recostamiento, mi nardo dio su olor. (L. 122)

Mientras que el rey en su rescobdo, mi nardo dio su olor.

\section{Cant 3, 8}

Todos ellos empuñada la espada, esperimentados en guerra; cada uno su espada sobre su muslo por el temor de las noches. (L. 306)

Todos ellos ceñidos de espada, abezados de guerra, cada uno su espada sobre su anca por miedo de las noches.

Los términos esperimentados y muslo empleados por el maestro salmantino no eran sino evidentes modernizaciones de las voces más arcaicas abezados y anca. Además, una prueba de que el agustino podía conocer aquella antigua versión la constituía la propia glosa del versículo. En ella, fray Luis no afirmó que los guerreadores poseían sus espadas empuñadas, sino ceñidas, al igual que en la biblia judeorromance: «tienen sus espadas ceñidas, que cuelgan sobre sus costados» (L. 311) ${ }^{43}$.

\section{Cant 4, 9}

Fray Luis: collar de tu cuello. (L. 319)

\footnotetext{
p. 461-479. En el primero de ellos el autor da cuenta, entre otros aspectos, de la creación de una auténtica poética bíblica durante el Siglo de Oro y de cómo los contenidos bíblicos se encauzan en moldes clásicos. En el segundo se analiza la conceptuación bucólica del Cantar bíblico.

43. El término «costado» aparecía además en la versión E5: cada uno la su espada sobr'el su costado.
} 
E5:

Prendísteme el corazón, con el uno de los tus ojos, con el un sartal de tu cuello ${ }^{44}$.

Cant 5,11

Fray Luis: $\quad$ Su cabeza como oro de Tibar, sus cabellos, crespos, negros como cuerbo. (B. 180)

$B N$ : Su cabeça como oro de Eufaz, sus vedijas crespas, negras como el cuervo.

Basten estos cuatro ejemplos como prueba última de la relación que sin duda existió entre la traducción del célebre maestro salmantino y las biblias judeorromances. Son muchas más las conexiones y aún más los ejemplos que podrían haberse añadido en defensa de aquella evidente dependencia. Con todo, los anteriores son prueba suficiente para demostrar que la versión de fray Luis no nació en medio de la nada y que debía más a la tradición, en este caso judeoespañola o sefardí, como lo era él en cierto modo, de lo que se ha creído. Y dicho sea de paso, quizás por esos mismos lazos tampoco fuese casual aquella deuda.

44. Con todo, en el comentario de fray Luis no faltaron traducciones como: «robaste mi corazón, con uno de los tus ojos, con un sartal del tu cuello». Esta versión es prácticamente igual a la traducción judeorromance y quizás se tratase de una de las primeras versiones del humanista. 
